\title{
Age-related effects on the neural correlates of autobiographical memory retrieval
}

\author{
Peggy L. St. Jacques ${ }^{\mathrm{a}, \mathrm{b}, *}$, David C. Rubin ${ }^{\mathrm{b}}$, Roberto Cabeza ${ }^{\mathrm{a}, \mathrm{b}}$ \\ ${ }^{a}$ Center for Cognitive Neuroscience, Duke University, Durham, NC, 27708, USA \\ ${ }^{b}$ Department of Psychology and Neuroscience, Duke University, Durham, NC, 27708, USA \\ Received 7 May, 2010; received in revised form 3 November 2010; accepted 5 Novembr 2010
}

\begin{abstract}
Older adults recall less episodically rich autobiographical memories (AM), however, the neural basis of this effect is not clear. Using functional MRI, we examined the effects of age during search and elaboration phases of AM retrieval. Our results suggest that the age-related attenuation in the episodic richness of AMs is associated with difficulty in the strategic retrieval processes underlying recovery of information during elaboration. First, age effects on AM activity were more pronounced during elaboration than search, with older adults showing less sustained recruitment of the hippocampus and ventrolateral prefrontal cortex (VLPFC) for less episodically rich AMs. Second, there was an age-related reduction in the modulation of top-down coupling of the VLPFC on the hippocampus for episodically rich AMs. In sum, the present study shows that changes in the sustained response and coupling of the hippocampus and prefrontal cortex (PFC) underlie age-related reductions in episodic richness of the personal past.
\end{abstract}

(C) 2012 Elsevier Inc. All rights reserved.

Keywords: Aging; fMRI; Autobiographical memory; Hippocampus; Prefrontal cortex; Episodic memory retrieval; Effective connectivity

\section{Introduction}

The main effect of healthy aging on autobiographical memory (AM) retrieval is attenuation in episodic richness, which refers to a decrease in the ratio of specific episodic details compared with broad semantic information. Although this behavioral effect has been observed in several studies (Levine et al., 2002; Piolino et al., 2002; St Jacques and Levine, 2007) its neural mechanisms are largely unknown. In particular, it is unknown when the age effect occurs during retrieval. A memory cue (Where did I see these data before?) triggers an effortful search process guided by semantic knowledge of one's own life (... the Cognitive Neuroscience Society meeting? ... Society for Neuroscience?), which eventually leads to successful recovery of a target memory (in a Society for Neuroscience poster...). Memory for the target might be elaborated by recovering additional episodic details (... it was early in the

\footnotetext{
* Corresponding author. Tel.: 617495 9031; fax: 6174963122.

E-mail address: peggyls@wjh.harvard.edu (P.L. St. Jacques).
}

morning... ). In the case of AM, search and elaboration processes can take as long as 15-30 seconds, which allows the use of functional MRI (fMRI) to disentangle the activations associated with these 2 phases (e.g., Addis et al., 2007; Daselaar et al., 2008). The present fMRI study investigated age-effects on search and elaboration processes during AM retrieval.

The age-related reduction in episodic richness could occur early during retrieval, while one is searching for the target memory, or late during retrieval, while one elaborates upon recovered information. Elaboration processes might be more sensitive to aging because they depend on an interaction between the recovery of specific details mediated by the hippocampus and strategic control processes mediated by the prefrontal cortex (PFC), and both processes, and their associated brain regions, are known to decline with aging (for a review see Dennis and Cabeza, 2008). For example, fMRI studies have shown that hippocampal activity related to recollection is attenuated by aging, such that older adults rely more on familiarity processes associated with other medial temporal lobe (MTL) regions (e.g., Cabeza et al., 2004; Daselaar et al., 2006). 
Aging also involves changes in strategic control processes linked to frontal activation, with under-recruitment observed during memory conditions that lack environmental support (e.g., Logan et al., 2002; Paxton et al., 2008), as well as compensatory over-recruitment (Cabeza, 2002). Furthermore, episodic richness is mediated by activations that occur late during AM retrieval (Svoboda et al., 2006; Cabeza and St Jacques, 2007), and relies on the recruitment of additional self-initiated retrieval processes (Daselaar et al., 2008). In contrast, an age-related reduction in early search processes might be less likely because AM search tends to be guided by semantic memory (Conway and Pleydell-Pearce, 2000), which is a memory function relatively well preserved in older adults (Craik and Jennings, 1992). In sum, aging may have less impact on the search strategy and cue specification processes in AM that are guided by semantic information, but have greater impact on the elaboration of AM which involves additional control processes that interact with the recovery of episodic information.

To investigate the neural basis of age-related differences in episodic richness during search and elaboration phases of AM retrieval we used a self-paced design in which young and older adults searched for an AM elicited by a generic cue word, pressed a key when the memory was found, and then elaborated on the memory until the end of the trial. After scanning, participants verbally described the memories they recalled in the scanner and objective analysis of these descriptions were used to determine episodic richness. We investigated the hypothesis that age-related declines in episodic richness are associated with reduced recovery of specific details mediated by the hippocampus and strategic control processes mediated by the PFC during elaboration.

\section{Methods}

\subsection{Participants}

There were 17 young (18-35 years of age) and 16 older participants (60-75 years of age), who were healthy, righthanded and without history of neurological or psychiatric episodes. All participants reported that they were not taking medication known to affect cognitive function, and older adult participants were screened for uncontrolled hypertension. Participants gave written informed consent for a protocol approved by the Duke University Institutional Review Board. One young adult and 1 older adult were excluded due to symptoms of depression as indicated by scores $>13$ on the Beck Depression Inventory (BDI; Beck and Steer, 1978). Furthermore, 2 young adults and 1 older adult were excluded from the analyses because of problems with completing the task as instructed. Thus, the reported results are based on data from 14 young ( 7 females; mean Age $=24.43, S D=3.73$ ) and 14 older ( 6 females; mean Age $=64.21, S D=2.86$ ) participants.

Demographic and psychometric data (Table 1) were obtained in a separate session within 1 week of the scanning session. All participants had obtained at least a
Table 1

Participant variables by age group

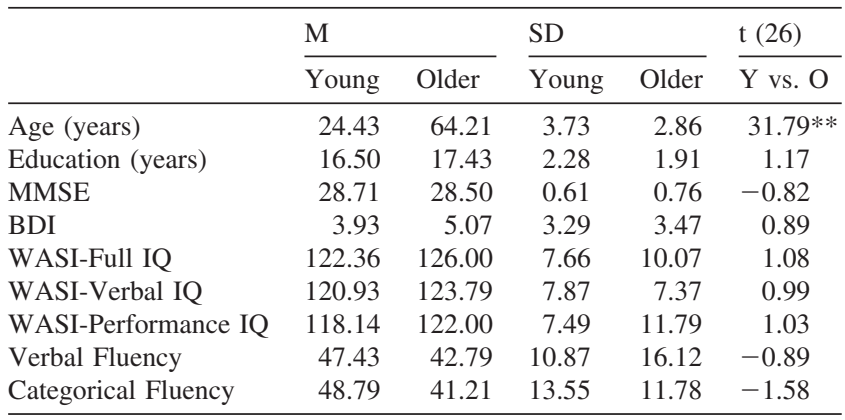

$* \mathrm{p}<.0001$.

secondary school education (12 years). Participants scored a minimum of 28 on the MiniMental State Exam (MMSE; Folstein et al., 1975) and a maximum of 11 on the BDI. There were no age-related differences in the number of years of education, MMSE, BDI, the Weschler Abbreviated Scale of Intelligence (WASI; Wechsler, 1999), verbal fluency (FAS), or categorical fluency (animal names and supermarket items).

\subsection{Materials}

Memory cues consisted of 60 emotionally arousing words selected from the affective norms for English words (ANEW) database (Bradley and Lang, 1999), such that there were 30 positive (Valence mean $=7.93, S D=0.45$; Arousal Mean $=5.96 ; S D=0.83$ ) and 30 negative (Valence Mean $=2.17, S D=0.52 ;$ Arousal Mean $=6.00 ; S D=1.03$ ) words that were equally arousing. In order to create auditory cues the words were recorded in a female voice and constrained to an equal duration of 1 second.

\subsection{Procedure}

The procedure was similar to Daselaar et al. (2008; also see Greenberg et al., 2005). During scanning participants were asked to search for AMs triggered by the auditory cue words. Participants were instructed to retrieve an AM that was specific to time and place. They indicated when a specific AM was found by making a response on the buttonbox and then continued to elaborate on the retrieved event in as much detail as possible for the rest of the trial. Thirty seconds following the onset of the auditory cue participants were given auditory instructions to rate the amount of emotion $(-4=$ negatively arousing to $+4=$ positively arousing) and reliving $(1=$ low to $8=$ high $)$ associated with the memory on an 8-point scale. Rating responses were selfpaced (up to 6 seconds) and separated by at least $0.5 \mathrm{sec}-$ onds. Participants underwent extensive training to familiarize them with the timing of the trials. There were 6 functional runs, with 10 memory cues in each run (5 positive words and 5 negative word), and an intertrial interval at least 1.5 to 7.5 seconds. Participants were instructed to keep their eyes closed for the duration of each run. 
Immediately following the scanning session participants were asked to provide a short title for the memory retrieved during scanning and to answer additional questions on a subset of the autobiographical memory questionnaire (e.g., Rubin et al., 2003). Participants were asked to date when the event had occurred (e.g., within the last day to $>10$ years ago), to indicate the amount of vividness or how clearly the event was remembered, the perspective or whether the memory was seen through their own eyes or through the eyes of an outside observer, the significance of the memory, and the physiological response during retrieval (e.g., heart pounding, etc.). Also, given that $\mathrm{AM}$ comprises many different types of events (Brewer, 1986; St. Jacques and Cabeza, in press) we asked participants to indicate whether the type of memory retrieved was a unique event (referring to a particular time and place), repeated event (memory for an event with multiple occurrences), extended event (occurring longer than one day), or semantic information (long-standing facts about one's own life).

Within 2 days of the scanning session, participants returned for an additional session in which they were cued by the title they had provided following the scanning session and asked to verbally recall the memories retrieved during scanning. The relatively short amount of time between scanning and verbal recall along with the use of idiosyncratic event titles helped to minimize potential changes in the properties of the memories between the 2 sessions. Participants were instructed to freely recall for at least 1 minute and were not provided with retrieval support from the experimenter. Following transcription each memory was coded for the number of episodic details and semantic details (similar to Levine et al., 2002). Raters were blind to the age-group of the participant. Episodic details reflected information that was specific to time and place, whereas semantic details reflected long-standing factual information about one's self or the world. Details were tallied for each category and the proportion of episodic details to the total details (episodic + semantic) was calculated for each memory in each subject as an estimate of the amount of episodic re-experiencing unbiased with respect to differences in protocol length.

\section{4. fMRI methods}

\subsubsection{Image acquisition}

Scanning was conducted using a 4T GE magnet. Auditory stimuli were presented using headphones and behavioral responses were recorded using an eight-button fiber optic response box (Resonance Technology, Northridge, CA). Head motion was minimized using foam pads and a headband. Anatomical scanning started with a T1-weighted sagittal localizer series, and then 3D fast spoiled gradient echo recalled (SPGR) structural images were acquired in the coronal plane $\left(256^{2}\right.$ matrix, $\mathrm{TR}=12.3 \mathrm{~ms}, \mathrm{TE}=5.4 \mathrm{~ms}$, flip angle $=20^{\circ}, \mathrm{FOV}=240,68$ slices, $1.9 \mathrm{~mm}$ slice thickness). Coplanar functional images were subsequently acquired using an inverse spiral sequence $\left(64^{2}\right.$ image matrix, $\mathrm{TR}=2000 \mathrm{~ms}, \mathrm{TE}=6 \mathrm{~ms}, \mathrm{FOV}=240$, flip angle $=$ $60^{\circ}, 34$ slices, $3.8 \mathrm{~mm}$ slice thickness, and $3.8 \times 3.8 \times 3.8$ $\mathrm{mm}$ voxel size).

\subsubsection{Image processing}

Image processing and analyses were performed using Statistical Parameter Mapping software in Matlab (SPM5; Wellcome Department of Imaging Neuroscience). Functional images were corrected for slice acquisition order, realigned to correct for motion artifacts, and then spatially normalized to a standard stereotactic space, using the template implemented in SPM5. No resampling was conducted during normalization. Subsequently, the functional images were spatially smoothed using an $8 \mathrm{~mm}$ isotropic Gaussian kernel. Coordinates are reported in Talairach space using a transformation from the Montreal Neurological Institute coordinates (Brett, Christoff, Cusack, and Lancaster, 2001).

\subsection{3. fMRI analyses}

To account for the fact that we used a self-paced paradigm in which participants indicated when they recalled a specific event, we implemented a flexible fMRI design in the context of the general linear model (GLM). The design distinguished 6 components in each trial: 4 transient and 2 sustained regressors. Transient regressors included the memory cue (immediately at onset of the trial), responserelated decision processes $(750 \mathrm{~ms}$ before the response indicating a memory was recalled), and the 2 ratings (second and third response). Sustained regressors included the memory search period (from trial onset to response) and the elaboration period (from response to the first rating). The transient regressors were modeled by convolving a canonical hemodynamic response function with a vector representing period onsets, while the sustained regressors were modeled by convolving the hemodynamic response function with a vector of a length that varied with that of the search and elaboration phases on each trial. In order to account for differences in the timing of activations due to the self-paced design, the response indicating that a memory was accessed determined the duration of the memory access period as well as the onsets of the response and elaboration periods. The use of the self-paced design reduced potential issues of multicollinearity between the regressors, and as an additional check we directly evaluated this by calculating the variance inflation factor (VIF; Cohen et al., 2003). For each regressor in each run and each participant, we extracted $R^{2}$, the squared multiple correlation between a single regressor and the other regressors, using design Magic (www.matthijs-vink.com/tools.html) and computed the VIF $\left(1 /\left(1-\mathrm{R}^{2}\right)\right)$. The standard cut-off value of 10 (Cohen et al., 2003) was used to exclude potential runs where multicollinearity between the regressors was an issue (e.g., Scheibe et al., 2006). On the basis of these results, only 4 runs were potentially problematic and these runs were excluded from the analysis. Data were high pass filtered using a cutoff of $128 \mathrm{~Hz}$, and global effects were removed (non-proportional scaling). Head 
motion was assessed prior to preprocessing, and no individual moved more than $3 \mathrm{~mm}$ in any direction, in any run.

To assess the validity of our flexible fMRI design (i.e., accuracy of the regressors and potential age-related differences in the timing of the hemodynamic response function), we investigated the time courses for fast and slow responses with respect to the self-paced button press indicating that a memory was formed. First, fast and slow responses were determined with respect to the mean reaction time in each subject. Second, a GLM was created in which trial onsets time-locked to the cue were modeled with a Finite Impulse Response basis set of peristimulus time bins of 2-second duration (equal to the TR) within each participant. The resulting parameter estimates were subsequently averaged across subjects for each peristimulus time bin, yielding estimates of fMRI signal change across the whole 48-second trial period for both fast and slow bins. Finally, for the actual validation, we used a region of interest (ROI) approach, focusing on auditory and motor cortex defined using the Talairach Daemon Atlas (Lancaster et al., 1997; Lancaster et al., 2000) implemented with PickAtlas software (Maldjian et al., 2003). The clusters showing significant $(p<0.005$, cluster size $>10)$ cue-related activity in the auditory cortex or response-related activity in the motor cortex based on the GLM analysis were defined as ROIs. These results show that, in both age groups, cue-related activity was not modulated by response time, whereas the peak of response-related activity shifted depending on whether it was a fast or a slow response (Fig. 1). Furthermore, the young and older adults showed similar peaks in auditory cortex, and a similar average peak response in the motor cortex. These findings are important because they potentially suggest that age-related differences in other brain regions, such as the hippocampus and the frontal lobes, may not be simply due to a global effect of aging on the hemodynamic response.

\subsubsection{Age-related effects during AM retrieval}

In order to determine the impact of aging on search and elaboration phases of AM retrieval we examined both age-invariant effects and age-related differences in each phase. For assessing age-invariant effects associated with the search and elaboration phases, a conjunction map was created thresholding each age group's random effects separately for each contrast (i.e., Elaboration or Search vs. implicit baseline) at $p=0.005$ and 10 voxels and then exclusively masking with the age-related differences at $p$ $=0.005$. This procedure yielded an activation map containing only those voxels that showed age-invariant effects during the search and elaboration phases. We assessed brain areas showing age-related differences by using a 2 sample $t$-test to compare young and older adults separately during the search and elaboration phases ( $p=$ 0.005 , with a cluster size $>10$ voxels), and then inclusively masked this statistical image with the correspond-

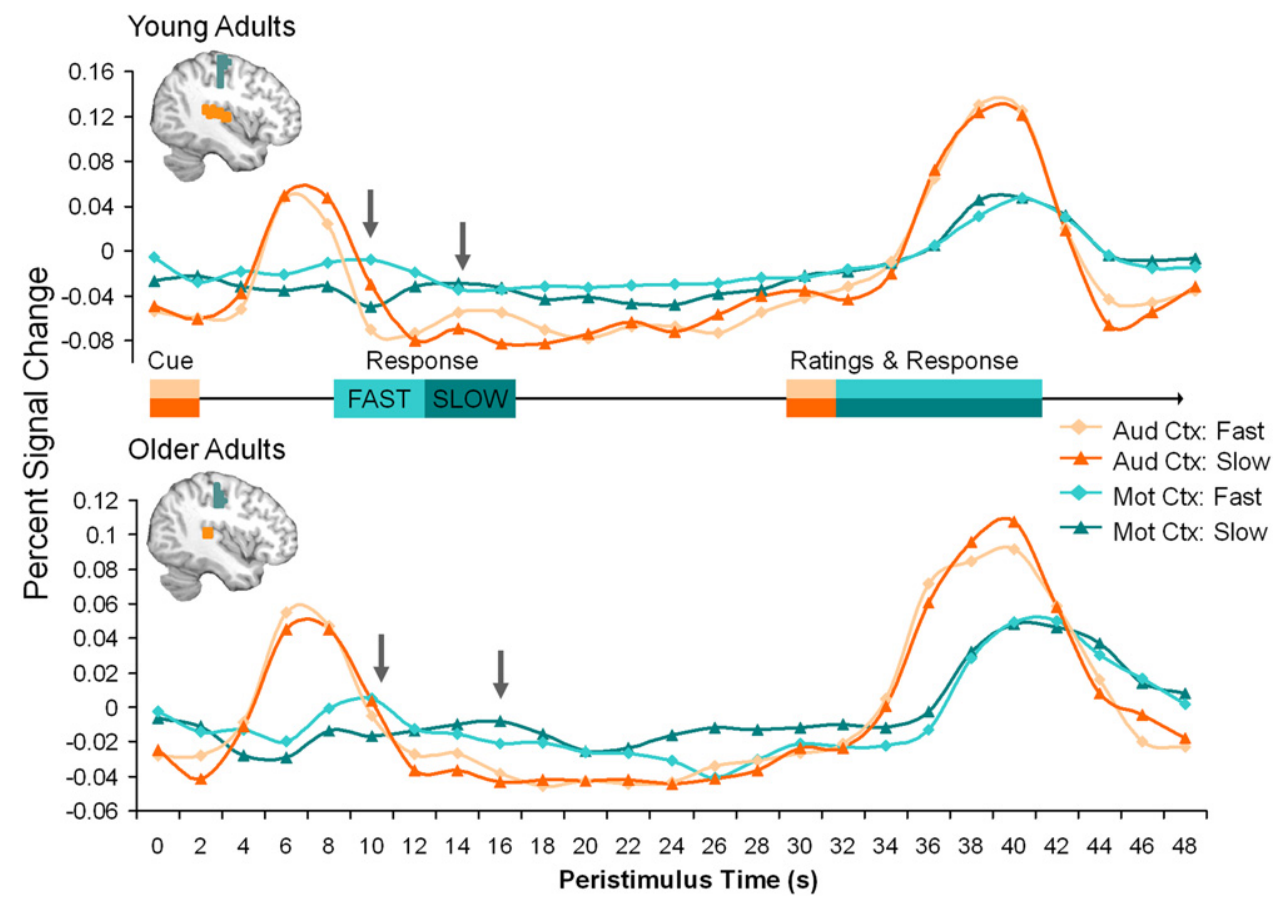

Fig. 1. Time Courses for Fast and Slow Responses. The time courses for fast and slow responses were nearly identical in the auditory cortex (audio ctx, orange/peach lines), and did not differ between age groups. In contrast, the time course for fast and slow responses was very different in the motor cortex (mot ctx, blue lines). The differences in peak latency in the motor cortex (gray arrows) for fast trials (light colors) and slow trials (dark colors) shows similar peaks in each age group, although there was a trend for slower responses in the older adults. 
ing statistical map for the group of interest at $p=0.005$. Thus, the resulting pattern of age-related differences in activity had to pass 2 hurdles: 1) the activation should be significant within 1 group, and 2) the activation should be significantly larger within 1 group compared with the other group. The threshold for whole-brain analysis was chosen to control for both type I and Type II errors rates (Lieberman and Cunningham, 2009). Given the a priori role of the hippocampus in AM retrieval (Maguire, 2001; Svoboda et al., 2006; Cabeza and St Jacques, 2007; McDermott et al., 2009; Spreng et al., 2009) and our predictions regarding its involvement in aging, we conducted an additional ROI analysis $(p=0.01)$ to examine both age-invariant and age-related differences using the Talairach Daemon Atlas Labels (Lancaster et al., 1997; Lancaster et al., 2000) implemented with PickAtlas software (Maldjian et al., 2003).

\subsubsection{Hippocampal-PFC Coupling}

In order to examine the effective connectivity between the hippocampus and PFC, we used dynamic causal modeling (DCM) implemented in SPM5 (Friston et al., 2003). First, we created 2 volumes of interest (VOIs) in the hippocampus and ventrolateral prefrontal cortex (VLPFC), based on the peaks from the age-related differences during elaboration and the sensitivity of these regions to episodic richness, using a sphere with an 8 -mm radius, which were adjusted for the task design (i.e., other contrasts in the model) in order to isolate the specific contrast of interest. Second, for each individual subject and replicated over the 6 sessions, we created a model space that included iterations for the location of the driving input and modulatory inputs by episodic richness on possible intrinsic connections between each region. Episodic richness was determined as those trials with a greater proportion of episodic to semantic details (i.e., $>50 \%$ ). Plausible models included combinations of the following manipulations: driving inputs (in the hippocampus, VLPFC or both regions), intrinsic connections (reciprocal, bottom-up only, top-down only) and modulatory inputs (reciprocal, bottom-up only, top-down only). The final model space included 27 models that were estimated for each participant and replicated over the 6 sessions. Third, we used a Bayesian Model Selection (BMS) implemented in SPM8 to select an optimal model separately within each age-group using random effects (Stephan et al., 2009). BMS involves calculating the probabilities of each of the models given the data and bases statistical inference on the value of the exceedance probability, which refers to the probability that a particular model is more likely than other models in the space. Finally, to assess group effects, the resulting individual participant coefficients were submitted to a two-sample $t$-test at $p<.05$.

\section{Results}

\subsection{Behavioral results}

Participants were able to recall an event matching the cue on more than $95 \%$ of trials (Table 2 for mean behavioral scores, standard deviations, $t$-scores, $p$-values, and effect sizes). There were no age-related differences in the online ratings of reliving or emotional arousal. However, older adults were slower to make emotional ratings and there was a trend for slower retrieval of AMs compared with young adults.

As predicted the older adults showed a reduction in the episodic richness, the proportion of episodic details to the total number of episodic and semantic details, during the retrieval of AMs, $t(26)=4.05, p<.0005$. There were no differences between the age-groups in the overall number of episodic and semantic details recalled, $t(26)=0.99, p=.33$, suggesting that the reported differences cannot be explained by group differences in verbosity. The values of the episodic richness scores indicated that memories retrieved by the older adults (mean $=0.51 S D=0.17)$ were $20 \%$ less episodically rich compared with young adults (mean $=0.72, S D=0.09$ ), and the effect size, $D=1.54$, is large according to Cohen's standards (Cohen, 1988). The large effect size of the agerelated differences in episodic richness compared with the small effect size of the reliving ratings $(D=-0.23)$ suggests that the latter were not sensitive enough to detect age effects (also see Rubin and Schulkind, 1997). Consistent with the finding of an age-related reduction in episodic richness, the older adults reported that they recalled a smaller proportion of unique AMs and a greater proportion of repeated AMs and semantic memories compared with young adults. There were no age-related differences in postscan ratings of vividness, significance of the memory, physiological responses or memory perspective. Although there were no age-related differences in the proportion of memories retrieved from the most recent periods (i.e., day, week), older adults retrieved more remote memories (i.e., $>10$ years), and young adults recalled more events from other periods (i.e., month, year, 5 years). The age-related difference in episodic richness could be related to the observed age-related differences in remoteness (Moscovitch et al., 2005; Cabeza and St. Jacques, 2007). However, there was no intraindividual correlation between remoteness and episodic richness when collapsed across age, $r=-0.04, t(26)=-1.20, p=0.24$, or separately in young adults, $r=-0.05, t(13)=-0.03, p=$ 0.54 , or older adults, $r=-0.05, t(13)=-1.32, p=0.21$, which suggests that more remote memories were not necessarily less episodically rich. This result might seem unexpected, because remote memories are sometimes associated with less episodic richness (Alvarez and Squire, 1994; Moscovitch et al., 2005). However, in the present study, remote memories were also self-selected, very accessible, and potentially more detailed than if retrieval was constrained to a specific lifetime and remote period (e.g., Cohen 
Table 2

Mean behavioral responses by age group

\begin{tabular}{|c|c|c|c|c|c|c|}
\hline & \multicolumn{2}{|l|}{ M } & \multicolumn{2}{|l|}{$\mathrm{SD}$} & \multirow{2}{*}{$\frac{\mathrm{t}(26)}{\mathrm{Y} \text { vs. O }}$} & \multirow{2}{*}{$\frac{\text { Effect size }}{\text { Cohen's D }}$} \\
\hline & Young & Older & Young & Older & & \\
\hline \multicolumn{7}{|l|}{ Scanning } \\
\hline AMs Retrieved & 0.99 & 0.97 & 0.02 & 0.03 & 1.45 & 0.57 \\
\hline Reaction Time (s) & 6.55 & 8.68 & 2.11 & 3.62 & -1.90 & -0.72 \\
\hline \multicolumn{7}{|l|}{ Reliving } \\
\hline Rating & 5.03 & 5.26 & 1.07 & 0.93 & -0.62 & -0.23 \\
\hline Reaction Time (s) & 2.49 & 2.96 & 0.60 & 0.66 & -2.00 & -0.75 \\
\hline \multicolumn{7}{|l|}{ Emotion } \\
\hline Rating & 2.53 & 2.28 & 0.33 & 0.37 & 1.74 & 0.71 \\
\hline Reaction Time (s) & 2.14 & 2.67 & 0.67 & 0.63 & $-2.09 *$ & -0.81 \\
\hline \multicolumn{7}{|l|}{ Post-Scanning Ratings } \\
\hline Vividness & 4.69 & 4.70 & 0.78 & 1.01 & -0.42 & -0.01 \\
\hline Significance & 3.00 & 3.23 & 0.79 & 0.95 & -0.68 & -0.26 \\
\hline Physiological Response & 2.31 & 1.73 & 0.99 & 0.77 & 1.74 & 0.65 \\
\hline \multicolumn{7}{|l|}{ Perspective } \\
\hline Own Eyes & 5.78 & 5.44 & 0.83 & 0.91 & -1.02 & 0.39 \\
\hline Observer & 2.37 & 2.38 & 0.92 & 0.90 & 0.05 & -0.01 \\
\hline \multicolumn{7}{|l|}{ Date of Memory } \\
\hline Day & 0.05 & 0.03 & 0.04 & 0.04 & 0.92 & 0.50 \\
\hline Week & 0.09 & 0.06 & 0.06 & 0.05 & 1.50 & 0.54 \\
\hline Month & 0.12 & 0.06 & 0.08 & 0.07 & $2.29 *$ & 0.80 \\
\hline Year & 0.26 & 0.15 & 0.09 & 0.08 & $3.20 * * *$ & 1.29 \\
\hline 5 years & 0.25 & 0.13 & 0.11 & 0.09 & $2.93 * *$ & 1.19 \\
\hline 10 years & 0.14 & 0.15 & 0.08 & 0.11 & -0.16 & -0.10 \\
\hline$>10$ years & 0.09 & 0.41 & 0.06 & 0.19 & $-6.07 * * * *$ & -2.27 \\
\hline \multicolumn{7}{|l|}{ Memory Type } \\
\hline Unique & 0.81 & 0.62 & 0.15 & 0.19 & $2.96^{* *}$ & 1.11 \\
\hline Repeated & 0.14 & 0.24 & 0.09 & 0.14 & $-2.22 *$ & -0.85 \\
\hline Extended & 0.05 & 0.12 & 0.06 & 0.15 & -1.66 & -0.61 \\
\hline Fact & 0.002 & 0.02 & 0.01 & 0.03 & -1.93 & -0.80 \\
\hline \multicolumn{7}{|l|}{ Verbal Recall } \\
\hline Episodic Richness & 0.72 & 0.51 & 0.09 & 0.17 & $4.05 * * * *$ & 1.54 \\
\hline Total Number of Details & 17.10 & 19.15 & 3.22 & 7.02 & -0.99 & 0.38 \\
\hline
\end{tabular}

$* \mathrm{p}<.05, * * \mathrm{p}<.01, * * * \mathrm{p}<.005, * * * * \mathrm{p}<.0005$.

and Faulkner, 1988; Dijkstra and Kaup, 2005; Rubin and Schulkind, 1997); thus, it is not so surprising that these remote events would vary in episodic richness. In sum, the behavioral results show that the episodic richness of AMs was greatly reduced in older adults. Below, we turn to the fMRI results to elucidate the potential neural bases underlying this age-related reduction in episodic richness.

\section{2. fMRI results}

\subsubsection{Age-invariant effects during AM retrieval}

During AM retrieval several age-invariant effects were observed during the search phase (Table 3). During search, both young and older adults recruited a number of the regions frequently found in AM retrieval (e.g., Cabeza and St Jacques, 2007; Svoboda et al., 2006) including the left VLPFC, left hippocampus, bilateral temporopolar cortex, bilateral retrosplenial cortex, and left parahippocampal cortex. During elaboration, a subset of these age-invariant search regions continued to remain online in both groups including the left parahippocampal cortex and the left retrosplenial cortex, and there was additional age-invariant recruitment of the left ventral parietal cortex (VPC). However, the pattern of age-related differences during elabora- tion suggested that the overall amount of activity recruited by the older adults was reduced when compared with the young adults.

\subsubsection{Age-related differences during AM retrieval}

Age-related differences were primarily observed during elaboration (Table 4). Compared with the age-invariant activity observed during the search phase, older adults showed less activity in the right hippocampus and left VLPFC (Fig. $2 \mathrm{~A})$. The reduction in recruitment of the right hippocampus and VLPFC suggests that fewer details may have been generated during elaboration in the older adults. Consistent with this idea, there was an age-related reduction in the additional recruitment of the right VPC, suggesting less internal attention driven by the recovery of memory details (Cabeza et al., 2008). Furthermore, there were additional age-related reductions observed in the recruitment of the left posterior cingulate, a region associated with episodic memory retrieval and self-referential processes (Wagner et al., 2005; Buckner and Carroll, 2007), and left DLPFC, associated with manipulation of the products of retrieval (Petrides, 2005). These results suggest an alteration in the recruitment of the AM retrieval network during elaboration of AMs in 
Table 3

Age-invariant effects

\begin{tabular}{|c|c|c|c|c|c|c|c|c|c|c|c|}
\hline \multirow[t]{2}{*}{ Region } & \multirow[t]{2}{*}{ BA } & \multirow[t]{2}{*}{$\mathrm{H}$} & \multicolumn{4}{|c|}{ Young } & \multicolumn{4}{|l|}{ Older } & \multirow[t]{2}{*}{ Voxels } \\
\hline & & & $\mathrm{x}$ & $\mathrm{y}$ & $\mathrm{z}$ & $\mathrm{T}$ & $\mathrm{x}$ & $\mathrm{y}$ & $\mathrm{z}$ & $\mathrm{T}$ & \\
\hline \multicolumn{12}{|l|}{ Search } \\
\hline \multirow[t]{2}{*}{ Ventrolateral PFC } & 45 & $\mathrm{~L}$ & -45 & 19 & 17 & 8.22 & -41 & 23 & 13 & 5.55 & 276 \\
\hline & 47 & $\mathrm{~L}$ & -33 & 22 & -4 & 7.14 & -48 & 29 & -11 & 5.34 & 276 \\
\hline Anterior Cingulate & 32 & $\mathrm{~L}$ & -7 & 20 & 41 & 10.47 & -15 & 13 & 38 & 6.50 & 48 \\
\hline \multirow[t]{2}{*}{ Temporopolar Cortex } & $38 / 21$ & $\mathrm{~L}$ & -52 & 3 & -16 & 6.06 & -52 & 3 & -19 & 4.61 & 73 \\
\hline & $38 / 21$ & $\mathrm{R}$ & 52 & -1 & -16 & 6.71 & 56 & 3 & -19 & 5.06 & 75 \\
\hline *Hippocampus & - & $\mathrm{L}$ & -26 & -22 & -9 & 3.70 & -19 & -26 & -8 & 4.35 & 21 \\
\hline Parahippocampus & - & $\mathrm{L}$ & -19 & -37 & -8 & 3.43 & -15 & -37 & -8 & 6.49 & 39 \\
\hline \multirow[t]{2}{*}{ Retrosplenial Cortex } & 30 & $\mathrm{~L}$ & -22 & -51 & 10 & 5.37 & -11 & -54 & 10 & 5.34 & 83 \\
\hline & 30 & $\mathrm{R}$ & 15 & -44 & 2 & 4.91 & 11 & -47 & 2 & 5.86 & 18 \\
\hline Cuneus & $17 / 18$ & $\mathrm{R}$ & 4 & -94 & 5 & 5.81 & 11 & -94 & 5 & 5.34 & 20 \\
\hline Midbrain & & $\mathrm{L}$ & -4 & -33 & -14 & 4.83 & -7 & -30 & -14 & 5.00 & 39 \\
\hline \multicolumn{12}{|l|}{ Elaboration } \\
\hline Retrosplenial Cortex & $29 / 23$ & $\mathrm{~L}$ & -7 & -58 & 13 & 9.24 & -11 & -54 & 13 & 3.72 & 50 \\
\hline *Hippocampus & - & $\mathrm{L}$ & -26 & -15 & -19 & 4.71 & -26 & -19 & -15 & 4.12 & 6 \\
\hline Parahippocampus & - & $\mathrm{L}$ & -26 & -37 & -11 & 6.82 & -26 & -30 & -14 & 4.17 & 19 \\
\hline Ventral Parietal Cortex & 39 & $\mathrm{~L}$ & -48 & -71 & 32 & 5.25 & -48 & -68 & 24 & 3.88 & 20 \\
\hline
\end{tabular}

Talaraich Coordinates Reported. BA, Brodmann's Area; H, Hemisphere.

* Region of Interest.

older adults, which might contribute to reductions in episodic richness. In sum, these findings are consistent with the idea that aging strongly impacts the rich elaboration of AMs.

We conducted 2 ancillary analyses in order to confirm that the age-related reduction during elaboration was linked to older adults' overall reduction in episodic richness and difficulty in engaging strategic retrieval processes. First, we examined activity only on those trials associated with higher episodic richness, which included AMs containing more episodic details than semantic details (i.e., $>50 \%$ episodic richness). Thus, this additional analysis included the major-

Table 4

Age-related differences

\begin{tabular}{|c|c|c|c|c|c|c|c|}
\hline Region & BA & $\mathrm{H}$ & $\mathrm{x}$ & $\mathrm{y}$ & $\mathrm{z}$ & $\mathrm{T}$ & Voxels \\
\hline \multicolumn{8}{|l|}{ Search } \\
\hline \multicolumn{8}{|l|}{ Young $>$ Older } \\
\hline Dorsomedial PFC & $8 / 32$ & $\mathrm{~L}$ & -7 & 20 & 44 & 4.39 & 47 \\
\hline Older $>$ Young & \multicolumn{7}{|c|}{ No Significant Voxels } \\
\hline \multicolumn{8}{|l|}{ Elaboration } \\
\hline \multicolumn{8}{|l|}{ Young $>$ Older } \\
\hline Ventrolateral PFC & 45 & $\mathrm{~L}$ & -56 & 19 & 10 & 3.34 & 11 \\
\hline Dorsolateral PFC & 9 & $\mathrm{~L}$ & -33 & 24 & 37 & 3.96 & 18 \\
\hline Dorsomedial PFC & $8 / 6$ & $\mathrm{C}$ & 0 & 21 & 55 & 3.54 & 11 \\
\hline Premotor Cortex & 6 & $\mathrm{~L}$ & -41 & -1 & 46 & 3.15 & 11 \\
\hline $\begin{array}{l}\text { Middle Temporal } \\
\text { Cortex }\end{array}$ & 21 & $\mathrm{R}$ & 56 & -12 & -12 & 3.44 & 15 \\
\hline $\begin{array}{l}\text { Ventral Parietal } \\
\text { Cortex }\end{array}$ & $40 / 22$ & $\mathrm{R}$ & 52 & -43 & 16 & 4.42 & 22 \\
\hline *Hippocampus & - & $\mathrm{R}$ & 26 & -15 & -12 & 3.01 & 6 \\
\hline $\begin{array}{l}\text { Posterior } \\
\quad \text { Cingulate }\end{array}$ & 31 & $\mathrm{~L}$ & -11 & -46 & 34 & 5.44 & 175 \\
\hline Older $>$ Young & \multicolumn{7}{|c|}{ No Significant Voxels } \\
\hline
\end{tabular}

Talaraich Coordinates Reported. BA, Brodmann's Area; H, Hemisphere. * Region of Interest. ity of AMs recalled in young adults (81\%), but only a subset of the memories recalled by older adults $(55 \%)$. The fMRI analysis revealed that when both groups recalled more episodically rich AMs there were fewer age-related differences during elaboration. Along with the regions previously showing age-invariant activity across all trials during elaboration (see Table 3), episodically rich AMs were also associated with age-invariant effects in the right hippocampus and left VLPFC (see Fig. 2B). These results suggest that the aforementioned age-related reductions in the right hippocampus and left VLPFC were related to older adults' overall difficulty in elaboration of episodically rich AMs. A few regions continued to show age-related reductions during the elaboration of episodically rich AMs, including the left posterior cingulate, left DLPFC, and dorsomedial PFC (see Table 4). Additional age-related differences were also observed in the left anterior PFC (Brodmann's Area 9; Talairach coordinates: $\mathrm{X}=-15, \mathrm{Y}=53, Z=32 ; T=$ $3.31,11$ voxels). In sum, these findings show that older adults recruited the right hippocampus and left VLPFC to a greater extent, which was equivalent to activation levels in young adults, on those trials in which they recalled more episodically rich AMs.

Second, we examined whether individual differences in strategic retrieval processes could account for group differences in the recruitment of the VLPFC during elaboration of AMs. Phonological and categorical fluency are associated with strategic retrieval processes involving the VLPFC (e.g., Gold and Buckner, 2002), and performance on these measures may account for age-related differences in the recall of AMs (Addis et al., 2009). Further, in the current study we found a significant correlation between average fluency scores and the mean response in the VLPFC (Fig. 

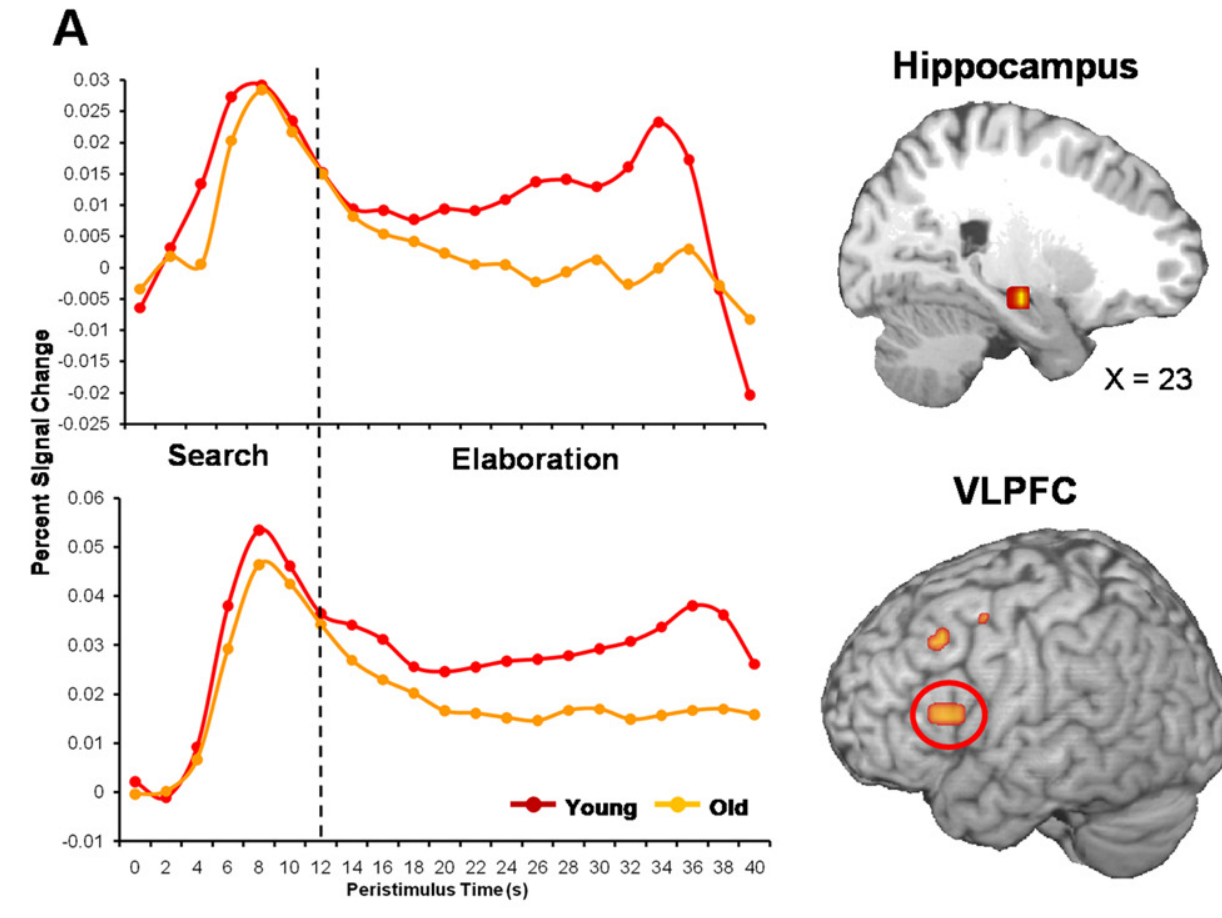

B
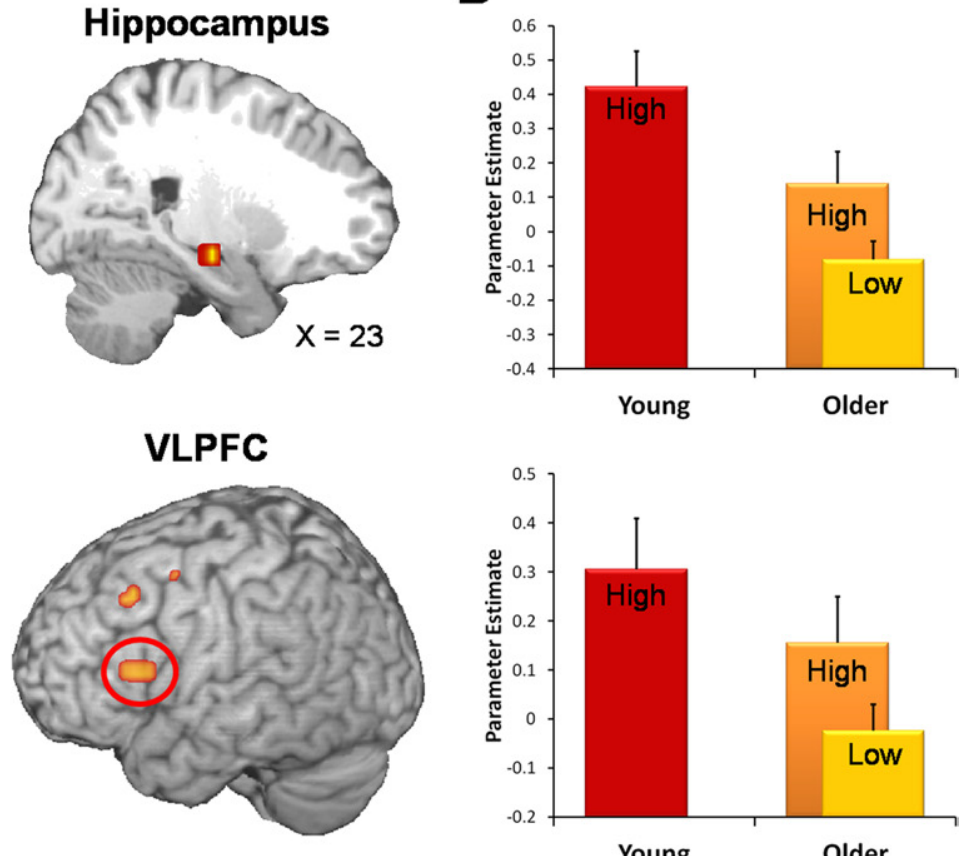

Fig. 2. Age Effects During AM Retrieval. (A) Age-invariant activity was observed in the right hippocampus and left VLPFC during search, but older adults showed reductions in this region during elaboration. Dotted line represents the peak of the average motor cortex response for the button press. Clusters of activation show areas where, compared with young adults, older adults had less recruitment during elaboration. (B) Age effects in the right hippocampus and left VLPFC were attenuated for highly episodic rich AMs. High and low refer to episodic richness.

3), $R=0.44, p<0.05$. Based on these observations, we included phonological and categorical fluency scores as covariates at the second level using an ANCOVA model to determine whether individual differences on strategic retrieval processes could account for the age-related differ-

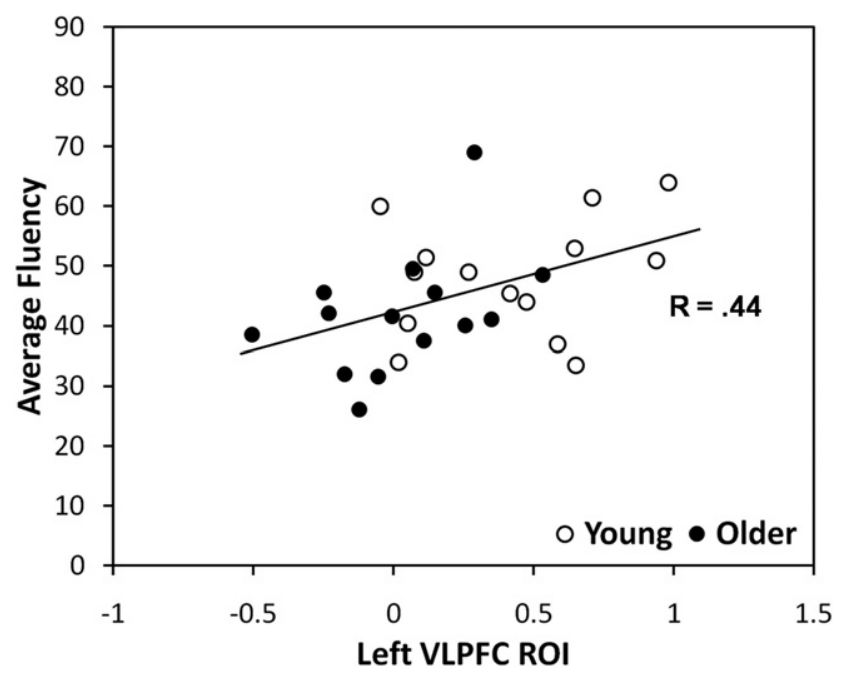

Fig. 3. Relationship Between Fluency and VLPFC. There was a significant correlation between the average fluency score (phonological and categorical) and the mean response in the VLPFC during elaboration. Activity in the VLPFC is expressed as a Beta Estimate. ROI, Region of Interest. ences in the VLPFC during elaboration. The results of the covariate analysis revealed that including categorical and phonological fluency reduced the age-related differences in the VLPFC, such that it was no longer significant at the specified threshold. This result suggests that the recruitment of the VLPFC may reflect strategic retrieval or controlled processes that operate during the elaboration of AMs and which are reduced in older adults. In contrast, the fluency measures did not account for the age-related effects observed in the hippocampus or the posterior cingulate, although it did somewhat reduce the spatial extent of agerelated differences in the DLPFC (from 18 to 8 voxels). In sum, these results support the interpretation that older adults rely less on strategic retrieval processes, as reflected by age-related reductions in the VLPFC during elaboration, which potentially contribute to the reduced episodic richness of AM.

\subsubsection{Hippocampal-PFC coupling}

The analyses above indicate that the right hippocampus and left VLPFC were the only regions showing both significant age-related reductions during elaboration and sensitivity to episodic richness. Given that these 2 brain regions may interact during episodic retrieval, our next fMRI analyses investigated the effect of aging on the coupling between these regions. It is important to note that the level of activity is not directly dependent upon coactivation among 
Table 5

Parameters in the Dynamic Causal Model

\begin{tabular}{cllll}
\hline & $\begin{array}{l}\text { Driving } \\
\text { input (C) }\end{array}$ & $\begin{array}{l}\text { VLPFC to } \\
\text { HIPP (A) }\end{array}$ & $\begin{array}{l}\text { HIPP to } \\
\text { VLPFC (A) }\end{array}$ & $\begin{array}{l}\text { Episodic } \\
\text { richness (B) }\end{array}$ \\
\hline $\begin{array}{l}\text { Young } \\
\text { Mean }\end{array}$ & 0.016 & 0.089 & 0.047 & 0.101 \\
SD & 0.013 & 0.083 & 0.050 & 0.100 \\
Older & & & & 0.008 \\
Mean & 0.003 & 0.043 & 0.018 & 0.067 \\
SD & 0.007 & 0.050 & 0.040 & \\
\hline
\end{tabular}

brain regions (Nyberg et al., 1996; Stephan, 2004). Although the right hippocampus and left VLPFC showed less activity during elaboration in the older adults, there was sufficient variance within each of these regions for effective connectivity analysis, as indicated by the observation of age-invariant effects here for highly episodically rich AMs.

We used DCM in order to distinguish potential agerelated differences in the direction of the hippocampal-PFC coupling (i.e., bottom-up vs. top-down) and the influence of episodic richness. Bayesian Model selection revealed the identical optimal model within each age group (for means and SD of parameters see Table 5). A DCM (Fig. 4) with a driving input on the VLPFC, reciprocal intrinsic connections between the hippocampus and the VLPFC, and modulation of episodic richness on the top-down influence of the VLPFC on the hippocampus, was the best model in both young adults (exceedance probability $=0.63$ ) and older adults (exceedance probability $=0.15$ ). These results show that in both age-groups it is the top-down rather than the bottom-up influence of the PFC on the hippocampus that modulates the episodic richness of AMs, which suggest that strategic retrieval processes importantly contribute to the recall of specific details during elaboration. Although the identical model was optimal in both age groups, there were age-related differences in the strength of the model parameters. There was a significant age-related reduction in the modulation of episodic richness by the top-down influence of the VLPFC on hippocampus, $t(26)=2.89, p<0.01$. Additionally, there were also age-related reductions in the driving input of the VLPFC, $t(26)=3.29, p<0.01$. These results suggest that the age-related reduction in episodic richness is associated with a decrease in the top-down modulation of the hippocampus by the VLPFC.

\section{Discussion}

The results of the present study suggest that the agerelated attenuation in the episodic richness of AMs is associated with difficulty in the strategic retrieval processes that guide the recovery of information during elaboration. There were 2 main findings supporting this idea. First, age-related differences in functional activations were greater during elaboration than during search in the hippocampus and VLPFC. The age-related differences were attenuated for highly episodically rich AMs and when individual differ- ences in strategic retrieval processes were included as covariates in the analysis. Second, there was an age-related reduction in the amount of top-down modulation of the VLPFC on the hippocampus by episodic richness during elaboration. These findings are discussed in separate sections below.

\subsection{Age-related effects during autobiographical memory retrieval}

To our knowledge this is the first fMRI study to examine age-invariant and age-related differences in search and elaboration processes underlying AM retrieval. We found that aging had less of an impact on functional activations during the initial search process, but a greater impact on later elaboration processes. The results of the present study are consistent with evidence from event-related potential studies showing that aging effects later retrieval processes in episodic memory (Trott et al., 1997; Trott et al., 1999; Wegesin et al., 2002, see also Li et al., 2004; Mark and Rugg, 1998), and to functional neuroimaging studies showing age-invariant effects in the retrieval network (Maguire and Frith, 2003; Morcom et al., 2007; Duverne et al., 2008), but they extend these findings by linking the age-related effects to both spatial and temporal components of retrieval.

The current results show preservation in older adults in the recruitment of search processes relying on semantic information (i.e., temporopolar cortices) and to the access of the memory trace (i.e., hippocampus and retrosplenial cortices; Botzung et al., 2008; Conway et al., 2001; Daselaar et
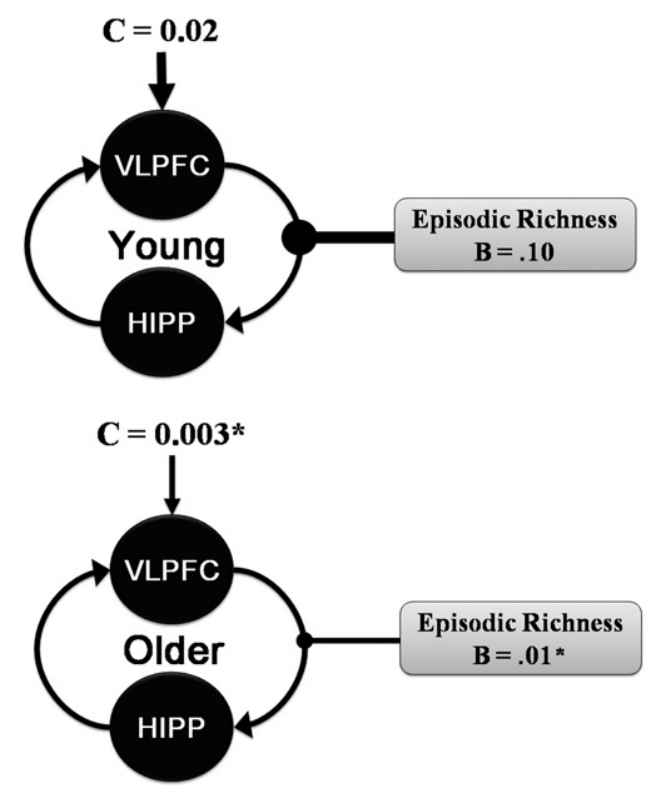

Fig. 4. Age-Related Differences in the DCM. A similar DCM was observed in both young and older adults. However, older adults showed a reduction in modulation of episodic richness by top-down influence of the VLPFC on hippocampus. There was also an age-related reduction in the driving input on the VLPFC. B, value of the modulatory input; $\mathrm{C}$, value of the driving input. 
al., 2008). A subset of the age-invariant regions observed during search continued to remain online during elaboration, in the left hippocampus, left parahippocampal cortex and left retrosplenial cortex. Conjointly, these regions have been linked to scene construction, the ability to generate a complex and coherent scene or event, which is commonly engaged across a number of tasks including AM (Hassabis and Maguire, 2007; Hassabis, Kumaran, Vann, Maguire, 2007). Thus, both age groups are potentially able to envision the context of the AM.

Older adults, however, had deficits in the recruitment of additional regions that support the rich elaboration of the constructed scene. First, although age-invariant activity was observed in the left hippocampus, older adults showed a reduction in the additional recruitment of the right hippocampus. In contrast to the current findings, Maguire and Frith (2003) found that aging led to a more bilateral pattern of hippocampal activity on an AM recognition task. Several methodological differences in the current study could potentially account for the observed differences such as the trial design (segregation of search and elaboration processes vs. no segregation of retrieval processes), the methodology to elicit memory (generic cues vs. prescan interview), the greater number of memories recalled (60 vs. 24), and the nature of retrieval (recall vs. true/false decision). Moreover, several studies have found bilateral recruitment of the hippocampus during AM retrieval in young adults (e.g., Addis, Moscovitch, Crawley, and McAndrews, 2004; Piefke et al., 2003; Piolino et al., 2004), and previous functional neuroimaging studies of AM have linked the recruitment of bilateral or right hippocampus to greater episodic richness (e.g., Piolino et al., 2008; Viard et al., 2007; see also Graham et al., 2003; Svoboda et al., 2006). Further, damage to the hippocampus can affect the detailed recall of AMs (e.g., St-Laurent et al., 2009; Steinvorth et al., 2005). Consistent with these ideas, the age-related reduction in the right hippocampus was also coupled with reductions in posterior regions that support the rich elaboration of AMs, such as the posterior cingulate (Addis et al., 2004; Levine et al., 2004; see also Levine et al, 2009) and the VPC (e.g., Levine et al., 2004; Berryhill, Phuong, Picasso, Cabeza, and Olson, 2007). Further, we found age-invariant activity in the right hippocampus when elaboration was restricted to highly episodically rich AMs, suggesting that this region is sensitive to variability in episodic richness.

Second, there was an age-related reduction in the sustained response in the left VLPFC, as well as in the additional recruitment of left DLPFC during elaboration. Lateral ventral and dorsal PFC regions work conjointly during AM retrieval (Cabeza and St Jacques, 2007) through the controlled recovery and manipulation of information, respectively (Petrides, 2005; Miller and Cohen, 2001). Supporting these roles, during elaboration the recovery of highly episodic rich AMs was associated with age-invariant VLPFC recruitment, whereas DLPFC continued to show an age- related reduction. Further, individual differences in strategic retrieval ability accounted for the age-related effects in the VLPFC, but had less effect on the DLPFC. Together, these results suggest that the VLPFC potentially contributes to age-related reductions in episodic richness via its role in strategic retrieval processing, whereas the DLFPC might contribute to additional age-related differences in the controlled manipulation of recovered information.

In sum, the results of the present study underscore the importance of decomposing the time course of retrieval processes when examining age-related effects by showing a differential pattern of functional activation across search versus elaboration processes in AM retrieval, particularly in the recruitment of the hippocampus and the PFC.

\subsection{Age-related effects on top-down modulation}

The findings from the effective connectivity analysis suggest that, despite a similar pattern of coupling between the hippocampus and VLPFC during elaboration, there was an age-related reduction in top-down modulation associated with episodic richness. The PFC is associated with strategic, controlled processes involving the recovery of information (Petrides, 2005; Miller and Cohen, 2001), which importantly contributes to the recall of episodically rich AMs (e.g., McKinnon et al., 2006; Smith et al., 2010). Here we show that individual differences in strategic retrieval ability as measured by categorical and phonological fluency accounted for age-related effects in the VLPFC during elaboration. There are several lines of evidence suggesting that aging impacts the strategic, controlled processes mediated by the frontal lobes, possibly as the result of an age-related deficit in dopamine function (for a review see West, 1996). According to the resources deficit theory of cognitive aging (Craik and Byrd, 1982) older adults are impaired on tasks that require self-initiated behavior such that providing environmental support (i.e., retrieval cues) can attenuate agedeficits. Consistent with this latter idea, providing additional retrieval cues during AM recall increases episodic richness (e.g., Levine et al., 2002). The present findings emphasize that age-related attenuations during elaboration are the result of the interaction between the PFC and hippocampus (cf. West, 1996). The hippocampus and PFC work together during memory retrieval (Moscovitch, 1992), and interactions between these regions are particularly important during more complex recall (for a review see Simons and Spiers, 2003) and contribute to the rich recollection of AMs across the lifespan (Viard et al., 2010). Further, lesion evidence shows that disconnecting these regions results in AM retrieval deficits (Levine et al., 1998).

The age-related reduction in the top-down modulation of the PFC on the hippocampus for episodically rich AMs is potentially one factor leading to behavioral differences during AM recall (Levine et al., 2002; Piolino et al., 2002; Piolino et al., 2006; St Jacques and Levine, 2007). Previous studies have associated the age-related reduction in the 
episodic richness of AMs with a more general aging phenomenon that tends to impair memory for specific details, but not memory for global information, and which has been associated with deficits in frontal function (for a review see Craik and Grady, 2002). However, to our knowledge, this is the first study to link the age-related reduction in episodic richness to a decline in the top-down influence of the PFC. Although older adults may recall less episodic information in their AMs, it is important to note that reduced reliance on specific details may infuse older adults' AMs with a richer narrative that imparts more wisdom or serves a different purpose (Labouvie-Vief, 1982; Mergler and Goldstein, 1983; James et al., 1998; Bluck, 2003) when compared with the AMs of young adults. In sum, the findings demonstrate that elaboration involves the interaction between the recovery of details mediated by the hippocampus and controlled strategic retrieval processes directed by the PFC, and suggest that older adults recall less episodically rich AM because of a reduction in top-down modulation.

\section{Conclusions}

In the present fMRI study, we examined age-related differences in episodic richness on the spatiotemporal dynamics of AM retrieval. Age-related reductions were primarily observed during the later elaboration processes of $\mathrm{AM}$ retrieval, with older adults showing a reduction in the recruitment of the hippocampus and PFC. Linking these results to the behavioral reductions in episodic richness in older adults, we found that functional activity in these regions was attenuated for AMs that were more episodically detailed. Further, we found an age-related reduction in the top-down modulation of the PFC on the hippocampus by episodic richness, possibly reflecting fewer controlled processes operating on the recovery of information in the hippocampus. In sum, the present findings suggest that the age-related deficit in the episodic richness of AMs is associated with an overall reduction in the rich elaboration of these memories, where older adults show less top-down modulation of the PFC on the hippocampus.

\section{Disclosure statement}

The authors certify that they have no actual or potential conflicts of interest regarding the research reported in this paper. The experimental protocol employed in the present study was approved for ethical treatment of human participants by the Institutional Review Board at Duke University Medical Center, and the experimental data were collected with the understanding and written consent of each participant.

\section{Acknowledgments}

We thank Amanda Miles for help with scanning, Nicole Dautel for help with coding and Philip A. Kragel for help with the analysis. This work was supported by the National Institute of Aging [RO1 AG023123 to DCR and RC, and RO1 AG019731 and AG023770 to RC], and to the Philip Jackson Baugh, Myra and William Waldo Boone, and Leadership in an Aging society Graduate Fellowships awarded to PLS. The corresponding author, PLS, is now at the Department of Psychology, Harvard University, Cambridge, MA, USA.

\section{References}

Addis, D.R., Sacchetti, D.C., Ally, B.A., Budson, A.E., Schacter, D.L., 2009. Episodic simulation of future events is impaired in mild Alzheimer's disease. Neuropsychologia 47, 2660-2671.

Addis, D.R., Wong, A.T., Schacter, D.L., 2007. Remembering the past and imagining the future: common and distinct neural substrates during event construction and elaboration. Neuropsychologia 45, 1363-1377.

Alvarez, P., Squire, L.R., 1994. Memory consolidation and the medial temporal lobe: a simple network model. Proc. Natl. Acad. Sci. USA 91, 7041-7045.

Beck, A., Steer, R., 1978. Beck Depression Inventory. Center for Cognitive Therapy, Philadelphia.

Bluck, S., 2003. Autobiographical memory: exploring its functions in everyday life. Memory 11, 113-123.

Botzung, A., Denkova, E., Ciuciu, P., Scheiber, C., Manning, L., 2008. The neural bases of the constructive nature of autobiographical memories studied with a self-paced fMRI design. Memory 16, 351-363.

Buckner, R.L., Carroll, D.C., 2007. Self-projection and the brain. Trends Cogn. Sci. 11, 49-57.

Cabeza, R., 2002. Hemispheric asymmetry reduction in older adults: the HAROLD model. Psychol. Aging 17, 85-100.

Cabeza, R., Ciaramelli, E., Olson, I.R., Moscovitch, M., 2008. The parietal cortex and episodic memory: an attentional account. Nat. Rev. Neurosci. 9, 613-625.

Cabeza, R., Daselaar, S.M., Dolcos, F., Prince, S.E., Budde, M., Nyberg, L., 2004. Task-independent and task-specific age effects on brain activity during working memory, visual attention and episodic retrieval. Cereb. Cortex 14, 364-375.

Cabeza, R., St Jacques, P.L., 2007. Functional neuroimaging of autobiographical memory. Trends Cogn. Sci. 11, 219-227.

Cohen, G., Faulkner, D., 1988. Life span changes in autobiographical memory. In Gruneberg, Morris, Sykes, Eds., 1988. Practical aspects of memory: Current research and issues $>$ Wiley, Chichester, UK, Vol. 1, pp. 277-282.

Cohen, J., 1988. Statistical Power Analysis for the Behavioral Sciences, 2nd Ed. Lawrence Erlbaum Associates, Hillsdale, NJ.

Cohen, J., Cohen, P., West, S.G., Aiken, L.S., 2003. Applied Multiple Regression/Correlation Analysis for the Behavioral Sciences, 3rd Ed. Lawrence Erlbaum Associates, Mahwah, NJ.

Conway, M.A., Pleydell-Pearce, C.W., 2000. The construction of autobiographical memories in the self-memory system. Psychol. Review 107, 261-288.

Conway, M.A., Pleydell-Pearce, C.W., Whitecross, S.E., 2001. The neuroanatomy of autobiographical memory: A slow wave cortical potential study of autobiographical memory. J. Mem. Lang. 45, 493-524.

Craik, F.I.M., Byrd, M., 1982. Aging and cognitive deficits: The role of attentional resources. In Craik, F.I.M., Trehub, S.E., Eds., Aging and Cognitive Processes. Plenum, New York, pp. 191-211.

Craik, F.I.M., Grady, C.L., 2002. Aging, memory, and frontal lobe functioning. In Stuss, D.T., Knight, R.T., Eds., Principles of Frontal Lobe Function. Oxford University Press, London, pp. 528-540.

Craik, F.I.M., Jennings, J.M., 1992. Human memory. In Craik, F.I.M., Salthouse, T.A., Eds., The Handbook of Aging and Cognition. Erlbaum, Hillsdale, NJ, pp. 51-110. 
Daselaar, S.M., Fleck, M.S., Dobbins, I.G., Madden, D.J., Cabeza, R., 2006. Effects of Healthy Aging on Hippocampal and Rhinal Memory Functions: An Event-Related fMRI Study. Cereb. Cortex 16, 17711782.

Daselaar, S.M., Rice, H.J., Greenberg, D.L., Cabeza, R., LaBar, K.S., Rubin, D.C., 2008. The spatiotemporal dynamics of autobiographical memory: neural correlates of recall, emotional intensity, and reliving. Cereb. Cortex 18, 217-229.

Dennis, N.A., Cabeza, R., 2008. Neuroimaging of healthy cognitive aging. In Craik, F.I.M., Salthouse, T.A., Eds. The Handbook of Aging and Cognition, 3rd Ed. Lawrence Erlbaum Associates, Mahwah, NJ, pp. $1-54$.

Dijkstra, K., Kaup, B., 2005. Mechanisms of autobiographical memory retrieval in younger and older adults. Mem. Cogn. 33, 811-820.

Duverne, S., Habibi, A., Rugg, M.D., 2008. Regional specificity of age effects on the neural correlates of episodic retrieval. Neurobiol. Aging 29, 1902-1916.

Folstein, M., Folstein, S., McHugh, P., 1975. Mini-Mental State: A practical method for grading the cognitive state of patients for the clinician. J. Psychiatr. Res. 12, 189-198.

Gold, B.T., Buckner, R.L., 2002. Common prefrontal regions coactivate with dissociable posterior regions during controlled semantic and phonological tasks. Neuron 35, 803-812.

Graham, K.S., Lee, A.C., Brett, M., Patterson, K., 2003. The neural basis of autobiographical and semantic memory: new evidence from three PET studies. Cogn. Affect. Behav. Neurosci. 3, 234-254.

Greenberg, D.L., Rice, H.J., Cooper, J.J., Cabeza, R., Rubin, D.C., LaBar, K.S., 2005. Co-activation of the amygdala, hippocampus and inferior frontal gyrus during autobiographical memory retrieval. Neuropsychologia 43, 659-674.

Hassabis, D., Kumaran, D., Vann, S.D., Maguire, E.A., 2007. Patients with hippocampal amnesia cannot imagine new experiences. Proc. Natl. Acad. Sci. U S A 104, 1726-1731.

Hassabis, D., Maguire, E.A., 2007. Deconstructing episodic memory with construction. Trends Cogn. Sci. 11, 299-306.

James, L.E., Burke, D.M., Austin, A., Hulme, E., 1998. Production and perception of "verbosity" in younger and older adults. Psychol. Aging $13,355-367$.

Labouvie-Vief, G., 1982. Growth and aging in life span perspective. Hum. Dev. 25, 65-79.

Lancaster, J.L., Summerin, J.L., Rainey, L., Freitas, C.S., Fox, P.T., 1997. The Talairach Daemon, a database server for Talairach Atlas Labels. Neuroimage 5(4:S633).

Lancaster, J.L., Woldorff, M.G., Parsons, L.M., Liotti, M., Freitas, C.S., Rainey, L., Kochunov, P.V., Nickerson, D., Mikiten, S.A., Fox, P.T., 2000. Automated Talaraich atlas labels for functional brain mapping. Hum. Brain Mapp. 10, 120-131.

Levine, B., Black, S.E., Cabeza, R., Sinden, M., McIntosh, A.R., Toth, J.P., Tulving, E., Stuss, D.T., 1998. Episodic memory and the self in a case of isolated retrograde amnesia. Brain 121, 1951-1973.

Levine, B., Svoboda, E., Hay, J.F., Winocur, G., Moscovitch, M., 2002. Aging and autobiographical memory: dissociating episodic from semantic retrieval. Psychol. Aging 17, 677-689.

Levine, B., Svoboda, E., Turner, G.R., Mandic, M., Mackey, A., 2009. Behavioral and functional neuroanatomical correlates of anterograde autobiographical memory in isolated retrograde amnesic patient M.L. Neuropsychologia. 47, 2188-96.

Levine, B., Turner, G.R., Tisserand, D., Hevenor, S.J., Graham, S.J., McIntosh, A.R., 2004. The functional neuroanatomy of episodic and semantic autobiographical remembering: a prospective functional MRI study. J. Cogn. Neurosci. 16, 1633-1646.

Li, J., Morcom, A.M., Rugg, M.D., 2004. The effects of age on the neural correlates of successful episodic retrieval: an ERP study. Cog. Affect. Biobehav. Neurosci. 4, 279-293.
Lieberman, M.D., Cunningham, W.A., 2009. Type I and Type II error concerns in fMRI research: re-balancing the scale. Soc. Cognit. Affect. Neuroscience. 4, 423-428.

Logan, J.M., Sanders, A.L., Snyder, A.Z., Morris, J.C., Buckner, R.L., 2002. Under-recruitment and nonselective recruitment: dissociable neural mechanisms associated with aging. Neuron 33, 827-840.

Maguire, E.A., 2001. Neuroimaging studies of autobiographical event memory. Philos. Transacations The R. Soc. Lond. B Biolological Sc. 356, 1441-1451.

Maguire, E.A., Frith, C.D., 2003. Aging affects the engagement of the hippocampus during autobiographical memory retrieval. Brain 126, 1511-1523.

Maldjian, J.A., Laurienti, P.J., Kraft, R.A., Burdette, J.H., 2003. An automated method for neuroantomic and cytoarchitectonic atlas-based interrogation of fMRI data sets. Neuroimage 19, 1233-1239 (WFU Pickatlas, version 1232. 1233).

Mark, R.E., Rugg, M.D., 1998. Age effects on brain activity associated with episodic memory retrieval. An electrophysiological study. Brain 121, 861-873.

McDermott, K.B., Szpunar, K.K., Christ, S.E., 2009. Laboratory-based and autobiographical retrieval tasks differ substantially in their neural substrates. Neuropsychologia 47, 2290-2298.

McKinnon, M.C., Black, S.E., Miller, B., Moscovitch, M., Levine, B., 2006. Autobiographical memory in semantic dementia: implication for theories of limbic-neocortical interaction in remote memory. Neuropsychologia 44, 2421-2429.

Mergler, N.L., Goldstein, M.D., 1983. Why are there old people. Senescence as biological and cultural preparedness for the transmission of information. Humal Dev. 26, 72-90.

Miller, E.K., Cohen, J.D., 2001. An integrative theory of prefrontal cortex function. Annu. Review Neurosci. 24, 167-202.

Morcom, A.M., Li, J., Rugg, M.D., 2007. Age effects on the neural correlates of episodic retrieval: increased cortical recruitment with matched performance. Cereb. Cortex 17, 2491-2506.

Moscovitch, M., 1992. Memory and Working-with-Memory. J. Cogn. Neurosci. 4, 257-267.

Moscovitch, M., Rosenbaum, R.S., Gilboa, A., Addis, D.R., Westmacott, R., Grady, C., McAndrews, M.P., Levine, B., Black, S., Winocur, G., Nadel, L., 2005. Functional neuroanatomy of remote episodic, semantic and spatial memory: a unified account based on multiple trace theory. J. Anat. 207, 35-66.

Nyberg, L., McIntosh, A.R., Cabeza, R., Nilsson, L.G., Houle, S., Habib, R., Tulving, E., 1996. Network analysis of positron emission tomography regional cerebral blood flow data: ensemble inhibition during episodic memory retrieval. J. Neurosci. 16, 3753-3759.

Paxton, J.L., Barch, D.M., Racine, C.A., Braver, T.S., 2008. Cognitive control, goal maintenance, and prefrontal function in healthy aging. Cereb. Cortex 18, 1010-1028.

Petrides, M., 2005. Lateral prefrontal cortex: architectonic and functional organization. Philos. Transact. R. Soc. Lond. B Biol. Sci. 360, 781795.

Piefke, M., Weiss, P.H., Zilles, K., Markowitsch, H.J., Fink, G.R., 2003. Differential remoteness and emotional tone modulate the neural correlates of autobiographical memory. Brain 126, 650-668.

Piolino, P., Desgranges, B., Benali, K., Eustache, F., 2002. Episodic and semantic remote autobiographical memory in ageing. Memory 10, 239-257.

Piolino, P., Desgranges, B., Clarys, D., Guillery-Girard, B., Taconnat, L., Isingrini, M., Eustache, F., 2006. Autobiographical memory, autonoetic consciousness, and self-perspective in aging. Psychol. Aging 21, 510525.

Piolino, P., Desgranges, B., Hubert, V., Bernard, F., Matuszewski, V., Chételat, G., Baron, J.C., Eustache, F., 2008. Reliving lifelong episodic autobiographical memories via the hippocampus: A correlative resting PET study in healthy middle-aged subjects. Hippocampus 18, 445459. 
Piolino, P., Giffard-Quillon, G., Desgranges, B., Chetelat, G., Baron, J.C., Eustache, F., 2004. Re-experiencing old memories via hippocampus: a PET study of autobiographical memory. Neuroimage 22, 1371-1383.

Rubin, D.C., Schrauf, R.W., Greenberg, D.L., 2003. Belief and recollection of autobiographical memories. Mem. Cogn. 31, 887-901.

Rubin, D.C., Schulkind, M.D., 1997. Distribution of important and wordcued autobiographical memories in 20-, 35-, and 70-year-old adults. Psychol. Aging 12, 524-535.

Scheibe, C., Wartenburger, I., Wustenberg, T., Kathmann, N., Villringer, A., Heekeren, H.R., 2006. Neural correlates of the interaction between transient and sustained processes: a mixed blocked/event-related fMRI study. Hum. Brain Mapp. 27, 545-551.

Simons, J.S., Spiers, H.J., 2003. Prefrontal and medial temporal lobe interactions in long-term memory. Nat. Rev. Neurosci. 4, 637-648.

Smith, S.J., Souchay, C., Conway, M.A., 2010. Overgeneral autobiographical memory in Parkinson's disease. Cortex 46, 787-793.

Spreng, R.N., Mar, R.A., Kim, A.S., 2009. The common neural basis of autobiographical memory, prospection, navigation, theory of mind, and the default mode: a quantitative meta-analysis. J. Cogn. Neurosci. 21, 489-510.

St-Laurent, M., Moscovitch, M., Levine, B., McAndrews, M.P., 2009. Determinants of autobiographical memory in patients with unilateral temporal lobe epilepsy or excisions. Neuropsychologia 47, 2211-2221.

St Jacques, P.L., Cabeza, R., in press. Neural correlates of autobiographical memory. In Ghetti, S., Bauer, P. J. Eds., Origins and Development of Recollection: Perspectives from Psychology and Neuroscience. New York, NY: Oxford University Press.

Steinvorth, S., Levine, B., Corkin, S., 2005. Medial temporal lobe structures are needed to re-experience remote autobiographical memories: evidence from H.M. and W.R. Neuropsychologia 43, 479-496.

Stephan, K.E., 2004. On the role of general system theory for functional neuroimaging. J. Anat. 205, 443-470.
Stephan, K.E., Penny, W.D., Daunizeau, J., Moran, R.J., Friston, K.J., 2009. Bayesian model selection for group studies. Neuroimage 46, 1004-1017.

Svoboda, E., McKinnon, M.C., Levine, B., 2006. The functional neuroanatomy of autobiographical memory: a meta-analysis. Neuropsychologia 44, 2189-2208.

Trott, C.T., Friedman, D., Ritter, W., Fabiani, M., 1997. Item and source memory: differential age effects revealed by event-related potentials. Neuroreport 8, 3373-3378.

Trott, C.T., Friedman, D., Ritter, W., Fabiani, M., Snodgrass, J.G., 1999. Episodic priming and memory for temporal source: event-related potentials reveal age-related differences in prefrontal functioning. Psychol. Aging 14, 390-413.

Viard, A., Lebreton, K., Chetelat, G., Desgranges, B., Landeau, B., Young, A., De La Sayette, V., Eustache, F., Piolino, P., 2010. Patterns of hippocampal-neocortical interactions in the retrieval of episodic autobiographical memories across the entire life-span of aged adults. Hippocampus 20, 153-165.

Viard, A., Piolino, P., Desgranges, B., Chetelat, G., Lebreton, K., Landeau, B., Young, A., De La Sayette, V., Eustache, F., 2007. Hippocampal Activation for Autobiographical Memories over the Entire Lifetime in Healthy Aged Subjects: An fMRI Study. Cereb. Cortex 17, 2453-2467.

Wagner, A.D., Shannon, B.J., Kahn, I., Buckner, R.L., 2005. Parietal lobe contributions to episodic memory retrieval. Trends Cogn. Sci. 9, 445453.

Wechsler, D., 1999. Wechsler Abbreviated Scale of Intelligence. Psychological Corporation, San Antonio, TX.

Wegesin, D.J., Friedman, D., Varughese, N., Stern, Y., 2002. Age-related changes in source memory retrieval: an ERP replication and extension. Cogn. Brain Res. 13, 323-338.

West, R.L., 1996. An application of prefrontal cortex function theory to cognitive aging. Psychol. Bull. 120, 272-292. 